\title{
The Regional Economic Impact of Changes in Import Oil Prices
}

\author{
D. J. Bjornstad, D. P. Vogt, and D. N. Stuckwish*
}

\section{INTRODUCTION}

Effective energy management policies will require changes in the way our society consumes energy. Because regions of the United States are economically specialized and often served by specialized energy markets, it is possible that spatial inequities will occur as new policies are implemented. Whether or not such inequities can be prevented, policy makers should address this issue and anticipate differential regional impacts as much as possible.

This paper focuses on how shifts in the price schedule for imported crude oil may influence regional distributions of population and employment. To conduct this analysis two models of the national economy - the Data Resources Incorporated (DRI) macroeconomic model and the Department of Energy Mid-Term Energy Forecasting System (DOE-MEFS)' ${ }^{1}$ are used to prepare national scenarios from which regional projections of population, employment, and energy consumption are developed. The regional projections are produced using the Oak Ridge National Laboratory MULTIREGION model (ORNL-MR) ${ }^{2}$ and the Oak Ridge National Laboratory Regional Energy Balance System (ORNL-REBS) ${ }^{3}$. The results reported here are drawn from a larger study supported by the DOE Office of Policy and Evaluation. ${ }^{4}$

The goal of this analysis is to determine whether regional effects of crude oil price shifts can be ascertained and if so, in what magnitude. Before turning to the analysis, however, several considerations which led to the adoption of the current approach should be discussed.

First, it is recognized that any exogenous effect on the economy is likely to have a significant impact on someone, but that for the most part national policy cannot consider effects at the individual or site-specific level. A broader regional and sectoral focus is required for general analysis of potential impacts. For the purposes of this study, Bureau of Economic Analysis (BEA) areas provide an appropriate regional scale. ${ }^{5}$ Working at a level of

\footnotetext{
tThis research was supported by the Office of Analytical Services of the Assistant Secretary for Policy and Evaluation under Union Carbide Corporation contract W-7405-eng-26 with the U.S. Department of Energy. The authors wish to thank Thomas Wilbanks of Oak Ridge National Laboratory and two anonymous reviewers for helpful comments on earlier drafts of this paper.
} 
spatial resolution this fine places restrictions on the sectoral level of disaggregation which can be effectively considered. Though the models operate with more sectoral detail, only the aggregate results for total population, employment (by manufacturing and non-manufacturing components), and total energy consumption are presented.

Second, price changes can cause short-run shifts in consumption as well as long-run changes in the structure of the economy's producing sectors. This study examines the long-term impacts of shifts in regional activity concentrations. It focuses on three growth paths or scenarios which the national economy is assumed to follow in response to three price schedules (high, medium, and low) for imported crude oil prices. To simplify things only two pairwise comparisons for each variable are considered: (1) the average annual growth rate between 1975 and 1995 (for the mid-price scenario) to illustrate the direction of change over time; and (2) the percent difference between the level of activity reached in the regions under the assumption of the high imported crude oil prices compared to the low imported crude prices to illustrate the range of impacts due to oil price changes.

Finally, while many analytical tools are available to examine price-related energy price impacts in a national setting (e.g., econometric demand models using estimated price elasticities $)^{6}$ virtually no such tools exist for comprehensive analysis at the small region level. The role of energy prices in determining industrial location is poorly understood at best. Both the DRI model and the MEFS model take price-related feedback effects into consideration in great detail at the national level. The ORNL-MR and ORNL-REBS models, however, do not consider direct energy price impacts at the regional level. Instead, the latter two models take changes in the level of economic activity and energy consumption which occur at the national level and combine them with historical regional determinants of economic and energy consumption behavior to produce regional projections.

The remainder of the paper is made up of three sections. The first contains a brief description of the input scenarios and the manner in which they are used. The second presents the empirical findings of the regional analysis and describes projected changes between 1975 and 1995 (mid-price scenario) and projected differences in the levels of activity achieved by various regions in the year 1995 under high- and low-imported crude oil price conditions. The final section summarizes the findings and interprets them from a policy perspective.

In general, three findings emerge. First, long-term shifts in population and employment will be more important determinants of regional socioeconomic patterns than new trends brought about by crude oil price changes. Second, regional activity shifts due to crude oil prices, while not dominant determinants of future activity levels, are discernable. They do not center in the old manufacturing belt, however, as do the impacts of short-term national fluctuations. Finally, although the level and composition of economic activity will continue to be the prime determinant of regional energy demands, price-re- 
lated adjustments are highly evident and are centered in regions most dependent on imported crude oil.

\section{GROWTH AND CHANGE IN THE NATIONAL ECONOMY}

The national projections used in this study were prepared by the Department of Energy. The projections provide a description of future levels and shifts in economic activity and energy consumption in response to imported crude oil price changes. ${ }^{7}$ In preparing the national scenarios, care was taken to isolate the impact of these price changes on the national economy so that within the limitations of the models themselves, all differences between scenarios could be attributed to price adjustments. More specifically, each scenario assumes a different rate of increase in world oil prices, starting from a base of $\$ 14.50 /$ barrel (all prices are measured in 1978 dollars) in 1975 . The lowprice scenario assumes that world oil prices begin to increase in 1988 at an annual rate of 2.5 percent, rising to a maximum of $\$ 25 /$ barrel. The mediumprice scenario assumes that world oil prices escalate at an annual rate of 5 percent beginning in 1985 and reach a maximum of $\$ 30 /$ barrel. The high-price

TABLE 1

National Totals for Selected Indicators

\begin{tabular}{|c|c|c|c|c|}
\hline & \multirow{2}{*}{$\begin{array}{c}\text { Base } \\
\text { Year } \\
1975\end{array}$} & \multicolumn{3}{|c|}{$\begin{array}{c}\text { Projected Values for } 1995 \text { Under Alternative } \\
\text { Scenarios }\end{array}$} \\
\hline & & Low Oil Price & Medium Oil Price & High Oil Price \\
\hline \multicolumn{5}{|l|}{ Economic Scenario } \\
\hline Population (thousands) & 213,448 & 245,076 & 245,076 & 245,076 \\
\hline Employment (thousands) & 86,855 & 122,851 & 121,499 & 119,763 \\
\hline Manufacturing & 19,867 & 24,231 & 23,917 & 23,488 \\
\hline Other & 66,988 & 98,620 & 97,589 & 96,275 \\
\hline \multicolumn{5}{|l|}{ Energy Scenario } \\
\hline Crude Oil Price (\$1978/barrel) & 14.50 & 25.00 & 30.00 & 35.00 \\
\hline Total Resource Use $\left(10^{1.5} \text { joules }\right)^{1}$ & 74,851 & 121,606 & 118,940 & 115,209 \\
\hline \multicolumn{5}{|l|}{ Resource Use by Fuel } \\
\hline Coal & 13,864 & 28,361 & 34,693 & 37,074 \\
\hline Oil & 34,235 & 49,754 & 43,230 & 36,990 \\
\hline Gas & 21,552 & 22,267 & 19,601 & 19,399 \\
\hline Nuclear ${ }^{2}$ & 1,909 & 16,748 & 16,743 & 16,982 \\
\hline Hydro, Solar, Geothermal ${ }^{2}$ & 3,291 & 4,478 & 4,673 & 4,764 \\
\hline \multicolumn{5}{|l|}{ Resource Use by Sector } \\
\hline Residential & 10,539 & 13,887 & 13,501 & 12,497 \\
\hline Commercial & 7,752 & 8,894 & 8,443 & 7,762 \\
\hline Industrial & 21,389 & 42,695 & 42,239 & 41,942 \\
\hline Transportation & 19,571 & 24,652 & 22,671 & 20,086 \\
\hline Electric Utilities $(\mathrm{Net})^{3}$ & 15,602 & 31,472 & 32,086 & 32,951 \\
\hline
\end{tabular}

${ }^{1} 1054.8$ joules equals a BTU; components may not add to total because of independent rounding. ${ }^{2}$ Nonfossil fuel electricity generation input requirements evaluated by fossil fuel equivalents.

${ }^{3} \mathrm{Net}$ electric utility requirements are fuel input minus electricity generated evaluated at 3412.8 BTU per KWH.

SOURCE: Unpublished data provided by the DOE/Office of Policy and Evaluation. 
scenario assumes that the world oil price increases begin in 1982 and escalate at a 8 percent rate reaching a maximum of $\$ 35 /$ barrel. These three sets of assumptions yield three growth paths for economic activity and energy that are referred to as the low, medium, and high (price) scenarios.

In principle, the procedure used to generate the scenarios may be easily described, though in practice the sequence of steps is somewhat more cumbersome. Import oil price assumptions are inserted into the DRI macroeconomic modtel. Because there are three sets of price assumptions, three unique model solutions - one for each price series - are prepared. This output is then passed to the operators of the MEFS where the relevant variables (basically income and value added) are disaggregated to the federal region level and inserted as exogenous drivers for the MEFS scenarios. The world oil price schedules and unique federal region economic activity levels are used to generate the three energy scenarios. It is the output from these two models which is the starting point for the regional analysis.

\section{National Economic Scenarios}

Although the DRI and the MEFS models compute equilibrium values for a broad range of variables, the only indicators presented in this analysis are changes in the level and composition of employment and the level of energy consumption. Table 1 summarizes the projections of these variables for the three scenarios.

Perhaps the most striking feature of the national economic projections is the relatively small difference in employment among the scenarios. Although total employment is projected to grow at an average annual rate of 1.0 percent between 1975 and 1995 (under the medium case), total employment differs by only 2.6 percent between the high and low scenarios in 1995 (see Table 2). This suggests that one or two recession years throughout the projection period could affect total employment as greatly as the import oil price shifts which underlie the analysis.

Manufacturing employment is projected to grow at an average rate of 0.9 percent per year over the period, and to differ between the high and low scenarios by 3.2 percent. Thus, areas characterized by either heavy concentrations of manufacturing or unusual rates of change in manufacturing activities will be much more sensitive to import oil price changes than average. Within the manufacturing sector, substantial differences in rates of growth and oil price sensitivities are present. For example, the petroleum refining sector is projected to decline as an employer over the period ( -0.5 percent) but to experience 37 percent less employment under high as compared to low scenarios. Because this sector is concentrated in a small number of regions, it will provide one source of regional variation under the alternate scenarios. The non-manufacturing sectors, on average, will grow more rapidly than will national employment but will experience only minor influence ( 2.4 percent difference) under the alternative rates of import oil prices. However, even here 
TABLE 2

Comparisons of Selected Indicators

\begin{tabular}{|c|c|c|}
\hline & $\begin{array}{c}\text { Reference Growth Rate } \\
\text { Average Annual Growth } \\
1975 \text { to } 1995 \\
\text { (Medium Price Scenario) } \\
\%\end{array}$ & $\begin{array}{c}\text { Scenario Range } \\
1995 \text { Projections } \\
\text { Percentage Difference } \\
\text { [(Low-High)/High] }\end{array}$ \\
\hline \multicolumn{3}{|l|}{ Economic Scenario } \\
\hline Population & 0.7 & 0.0 \\
\hline Employment & 1.7 & 2.6 \\
\hline Manufacturing & 0.9 & 3.2 \\
\hline Other & 1.9 & 2.4 \\
\hline \multicolumn{3}{|l|}{ Energy Scenario } \\
\hline Crude Oil Price & 3.7 & -28.6 \\
\hline Total Resource Use & 2.3 & 5.6 \\
\hline \multicolumn{3}{|l|}{ Resource Use by Fuel } \\
\hline Coal & 4.7 & -23.5 \\
\hline Oil & 1.2 & 34.5 \\
\hline Gas & -0.4 & 14.8 \\
\hline Nuclear & 11.5 & -1.4 \\
\hline Hydro, Solar, Geothermal & 1.8 & -6.0 \\
\hline \multicolumn{3}{|l|}{ Resource Use by Sector } \\
\hline Residential & 1.2 & 11.1 \\
\hline Commercial & 0.4 & 14.6 \\
\hline Industrial & 3.5 & 1.8 \\
\hline Transportation & 0.7 & 22.7 \\
\hline Electric Utilities & 3.7 & -4.5 \\
\hline
\end{tabular}

there is subsector variation. For example, employment in the wholesale-retail sector is projected to grow at above-average rates ( 2.3 percent per year) over the projection period and also exhibit above-average sensitivity to import oil price differences (4.3 percent difference).

\section{National Energy Scenarios}

Total energy consumption is projected to grow by 2.3 percent per year between 1975 and the 1995 medium scenario. A 5.6 percent difference in energy consumption levels is projected to exist between the 1995 high- and low-price scenarios. Thus, energy consumption growth roughly parallels that of employment, but is more sensitive to imported crude prices than employment growth.

Nuclear energy to generate electricity is projected to experience the most rapid growth over the period but to vary only slightly in response to import oil prices. Overall, electrical generation is projected to more than double over the next 20 years, with little import price sensitivity. The "swing" fuels in these scenarios are coal and natural gas. Coal use is expected to grow by 150 percent between 1975 and 1995 (medium case), while natural gas is projected to 
decline by nearly 10 percent. Coal usage is closely tied to import oil prices, and under the low-price scenario 24 percent less coal is used than under the high-price scenario. In contrast, 15 percent more natural gas is used for the low oil price case than the high case in 1995 . Petroleum products consumption is projected to increase between 1975 and the 1995 medium case, but this growth is sensitive to the level of world oil prices; thirty-five percent less petroleum will be used under the high-price case than the low-price case in 1995.

The industrial sector exhibits both a high rate of growth and low-import price sensitivity. Lower rates of growth are evident in the residential, commercial, and transportation sectors, but price sensitivities are higher in these than in the industrial sector. The gasoline-intensive transportation sector is particularly sensitive to the price changes and holds particular importance for the regional analysis.

Because growth in the industrial sector will lead to increased energy consumption, the location of industrial activities will play a large role in the intertemporal changes which individual regions will undergo. Among scenarios, however, little change in manufacturing activity levels is evident, and the spatial differences in energy consumption impacts from this source will be minimal. In contrast, trends in population change will have lesser impacts on the growth rates of energy consumption, but will account for a greater proportion of the differences among the scenarios, particularly for gasoline since the regional consumption patterns for this fuel are primarily determined by population levels.

\section{REGIONAL ANALYSIS OF NEP-2 BASE CASE SCENARIOS}

The changes that individual regions will experience from imported crude oil price increases are dependent on a number of factors. The composition of activity and the growth trends in each region play an important role in determining these changes since the intensity of fuel use varies considerably among industries. One should also expect spatial patterns of historical fuel choice to dominate the location of impacts caused by fuel-specific price changes. Sometimes a region's economic maturity conditions its response to stimuli. Studies of short-term economic cycles frequently conclude that older centers of manufacturing suffer most in short-term economic downturns. ${ }^{8}$ The current long-term focus should provide evidence of whether such areas as the "manufacturing belt" or the "sunbelt" are projected to fare differently in the face of sustained change than that alleged during short-term fluctuations.

Changes in the rate at which regions use energy are dependent on changes in the type and level of economic activity residing in each region and on the choices which economic agents make regarding fuel choice and intensity of energy use. To project these choices, the current approach is to distribute the equilibrium energy consumption information produced by the MEFS system using the ORNL-REBS. Fortunately, this task is simplified since MEFS pro- 
TABLE 3

Summary of Regional Growth Rates Under the Mid Oil Price Scenario (1975 to 1995$)$

\begin{tabular}{lcccc}
\hline & $\begin{array}{c}\text { Mean } \\
\text { Growth Rate } \\
\%\end{array}$ & $\begin{array}{c}\text { Standard } \\
\text { Deviation } \\
\%\end{array}$ & $\begin{array}{c}\text { BEA's* } \\
\text { Above Mean } \\
\%\end{array}$ & $\begin{array}{c}\text { BEA's* } \\
\text { Below Mean } \\
\%\end{array}$ \\
\hline Population & 0.9 & 0.8 & 14 & 14 \\
Total Employment & 2.0 & 0.9 & 13 & 16 \\
$\quad$ Manufacturing & 2.4 & 1.8 & 10 & 15 \\
$\quad$ Other & 1.9 & 1.1 & 13 & 12 \\
Energy Consumption & 1.4 & 0.8 & 18 & 19 \\
\hline
\end{tabular}

*Above and below average is defined as greater or less than one standard deviation from the mean.

vides outputs at the federal region level. To prepare BEA level projections, REBS creates energy-weighted indexes for each MULTIREGION economic sector based on projected levels of economic activity and historical energy use per worker patterns. It is assumed that price related allocations occur between federal regions but within federal regions, energy consumption levels are primarily determined by the level and composition of activity.

\section{Regional Growth Under the Medium Crude Oil Price Scenario}

Table 3 shows the first of the two types of information to be examined in this section. These data summarize projected population, employment and energy consumption information in terms of typical regional changes (mean), the spread about the mean (standard deviation), and the degree of normality with which this spread occurs (percent above and below mean). The entry for each variable heading (e.g., population) presents statistics for the average annual growth rate between 1975 and 1995 mid-price case.

The second type of information considered is the spatial configuration of the regional growth rates (see, for example, Fig. 1). Frequently, growth rates and mean deviations appear rather undistinguished by themselves, but form distinct spatial patterns. In the analysis which follows, both types of information are used to explain the complicated interactions between energy and regional economies.

Turning first to the broad indicators of economic activity-population and employment-it is evident that modifications in the distribution of people are less than those for jobs. The population of the average BEA area is projected to grow by about 0.9 percent per year while, on average, employment is projected to increase by 2.0 percent. Fig. 1 shows the highly regular concentrations of above and below average rates of population change which essentially trace out the boundaries of the "snowbelt-sunbelt" transition. Above average rates of increase are projected for broad areas of the west (except California) 


\section{GROWTH RATES IN POPULATION FROM 1975 TO 1995 MEDIUM OIL PRICE SCENARIO}

$M$ < 0.1269

$\square 0.1269-1.7379$

$>1.7379$

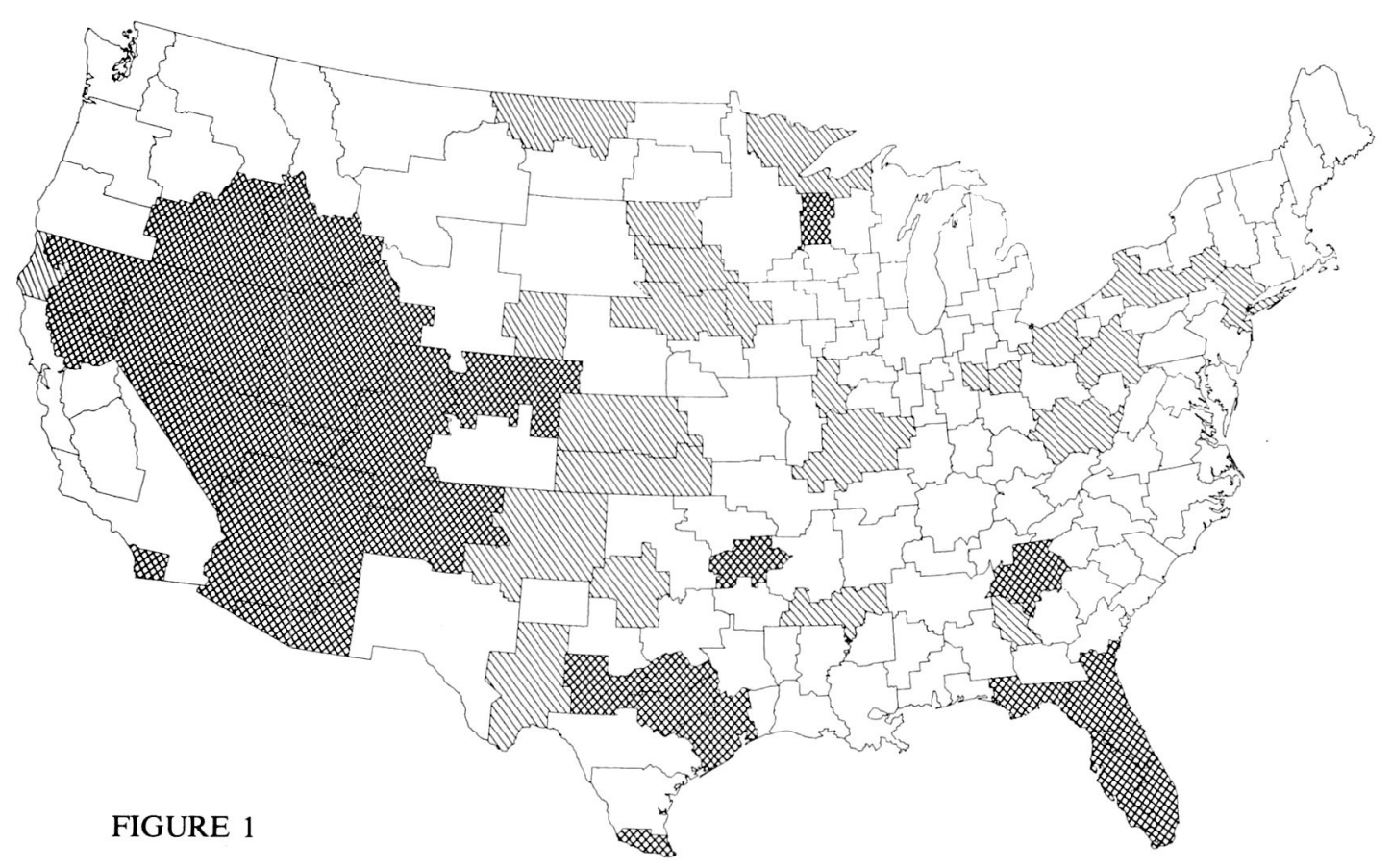

and for parts of Texas, Arkansas, and Georgia, as well as for most of Florida. Below average rates of growth dot the Great Lakes' manufacturing belt and are generally scattered throughout the midwest.

Because the population growth rates and changes just examined are closely related to growth rates and changes in total employment one should expect the location of each to coincide. Indeed, the patterns of Fig. 2 virtually duplicate those of Fig. 1.

The employment summary statistics in Table 3 indicates a greater average growth rate for manufacturing than in the non-manufacturing activities over the set of BEA areas. However, at the national level the non-manufacturing sectors were projected to exceed the growth of manufacturing.

This disparity indicates that the regional growth rates are highly influenced by the size distribution of the regions and the fact that manufacturing employment in smaller regions is projected to grow more rapidly than in larger regions. This also results in a higher standard deviation among regions in the 


\section{GROWTH RATES IN TOTAL EMPLOYMENT FROM 1975 TO 1995 MEDIUM OIL PRICE SCENARIO}

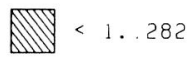

$\square 1.1282-2.8788$

$>2.8788$

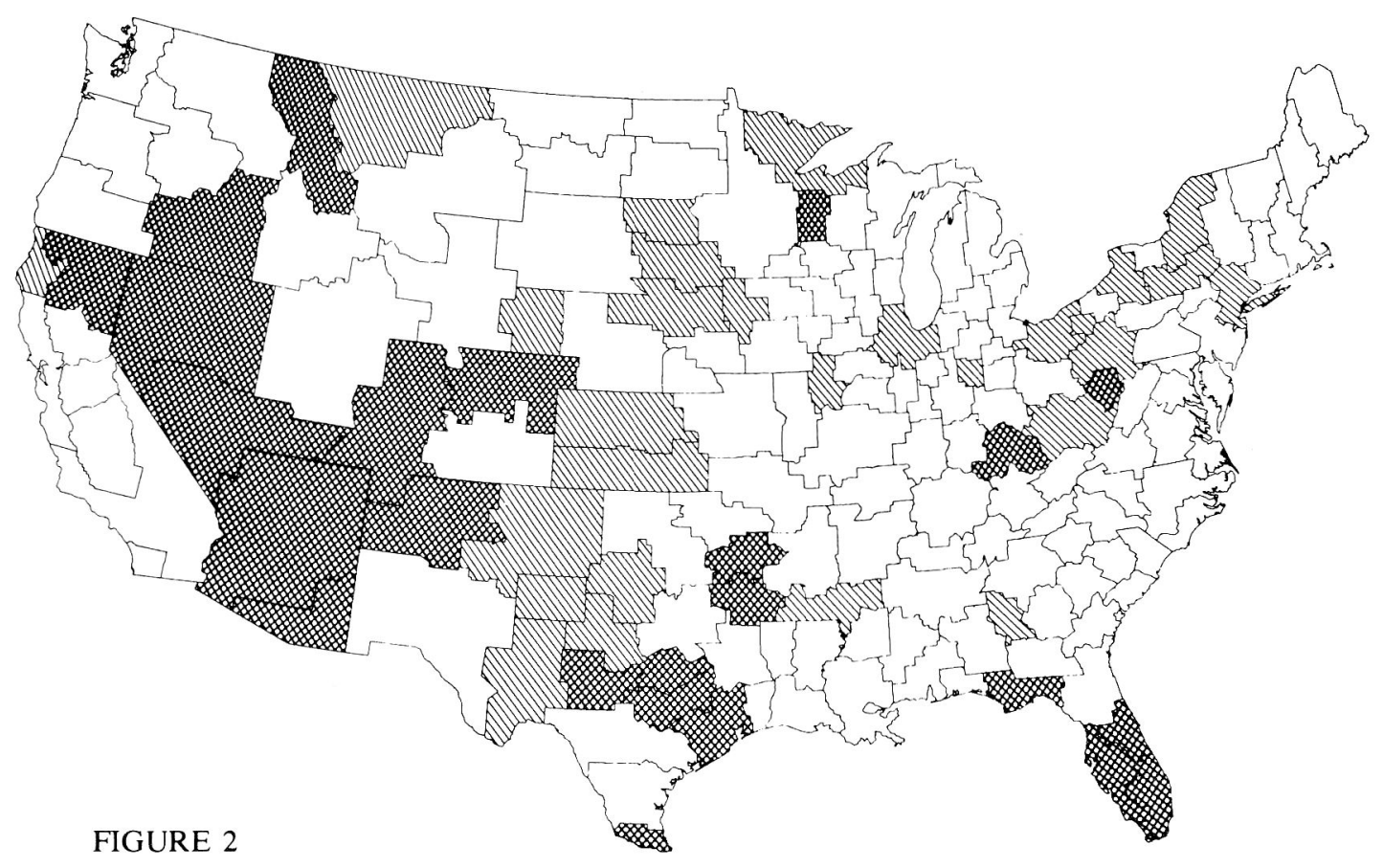

rate of growth of manufacturing activity than in the rate of growth of nonmanufacturing activity. There is a greater sensitivity in the manufacturing sectors to changes in the price of energy than in the non-manufacturing sectors. To understand the implications of these averages, however, requires understanding the spatial dimension of employment shifts as well.

Fig. 3 indicates that the projected spatial patterns of manufacturing activity are almost stereotypical. Below average rates of growth are projected for New England and much of the Great Lakes area, and above average rates of growth are projected along the southern seaboard and Gulf Coast, as well as throughout Texas and a scattering of predominantly rural areas in Nevada, Nebraska, and North Dakota.

It is also necessary to examine the patterns projected for non-manufacturing activity, particularly since the manufacturing change explains only a portion of the aggregate employment change. On average, both growth rates and scenario differences are more uniform for non-manufacturing employment 


\section{GROWTH RATES IN MANUFACTURING EMPLOYMENT FROM 1975 TO 1995 MEDIUM OIL PRICE SCENARIO}

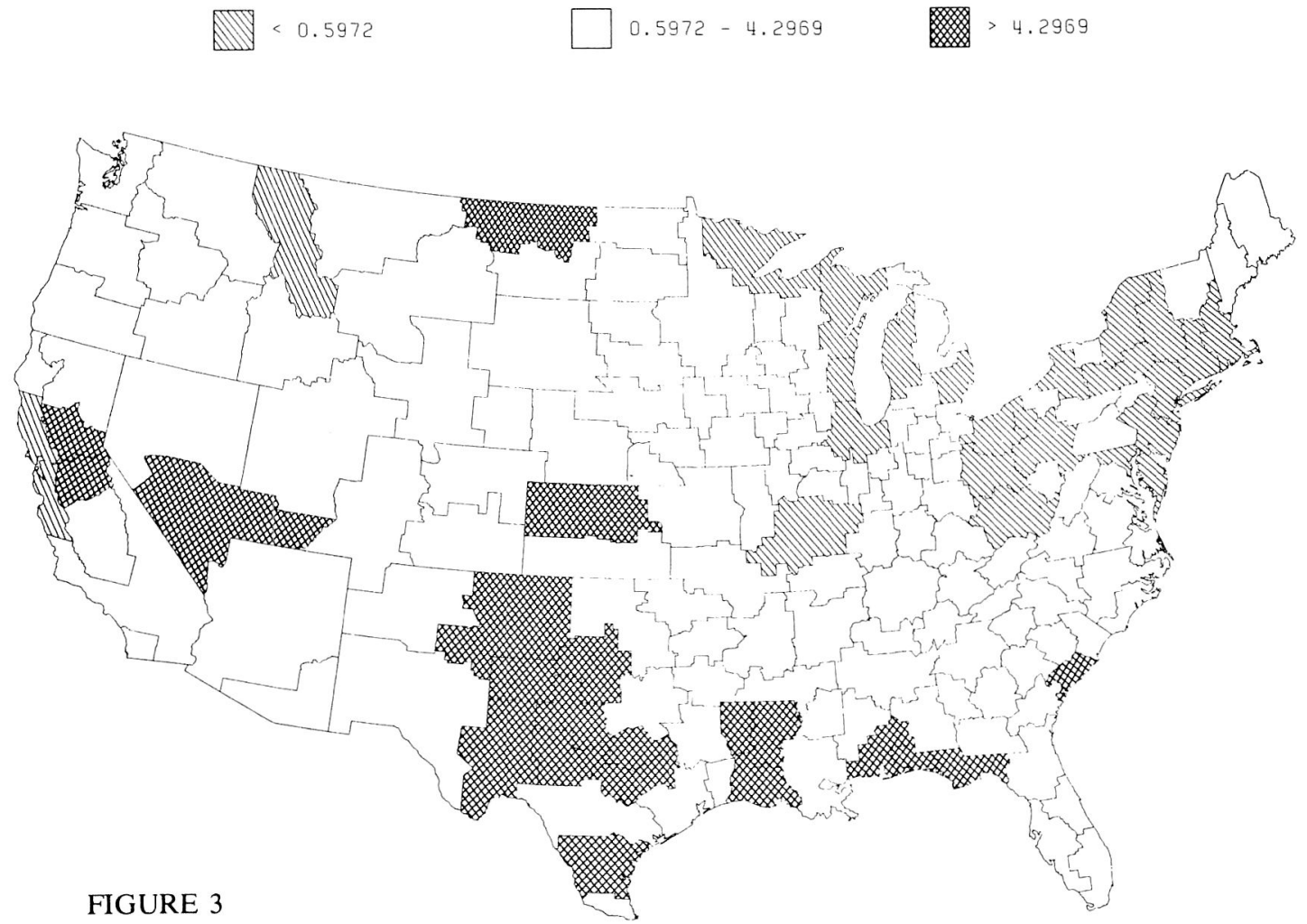

than for manufacturing activity (Fig. 4). Moreover, in spatial terms nonmanufacturing activity differs substantially from manufacturing activity. Except for California, much of the west and Florida are projected to grow at above average levels, with rapid growth also evident in portions of Texas, Georgia, and other scattered regions. Below average growth rates are found largely in the midwest, but are also found in portions of the south, including western Texas. Thus, growth in the west appears not to be driven by manufacturing activity. Manufacturing decline in the north has not led to projections of below average non-manufacturing growth rates.

Table 3 indicates that the average annual rate of energy consumption growth over the projection period is 1.4 percent, a rate somewhat below the average growth in total employment. ${ }^{9}$ As was true for the economic projections, departures from the average growth rate of greater than one standard deviation are uniformly distributed, but are noticeably larger than those for the economic projections. This most likely arises because the rate of energy 


\section{GROWTH $\frac{\text { RATES IN OTHER EMPLOYMENT }}{\text { FROM } 1975 \text { TO } 1995}$ \\ MEDIUM OIL PRICE SCENARIO}

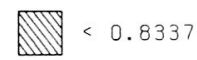

$\square 0.8337-2.9531$
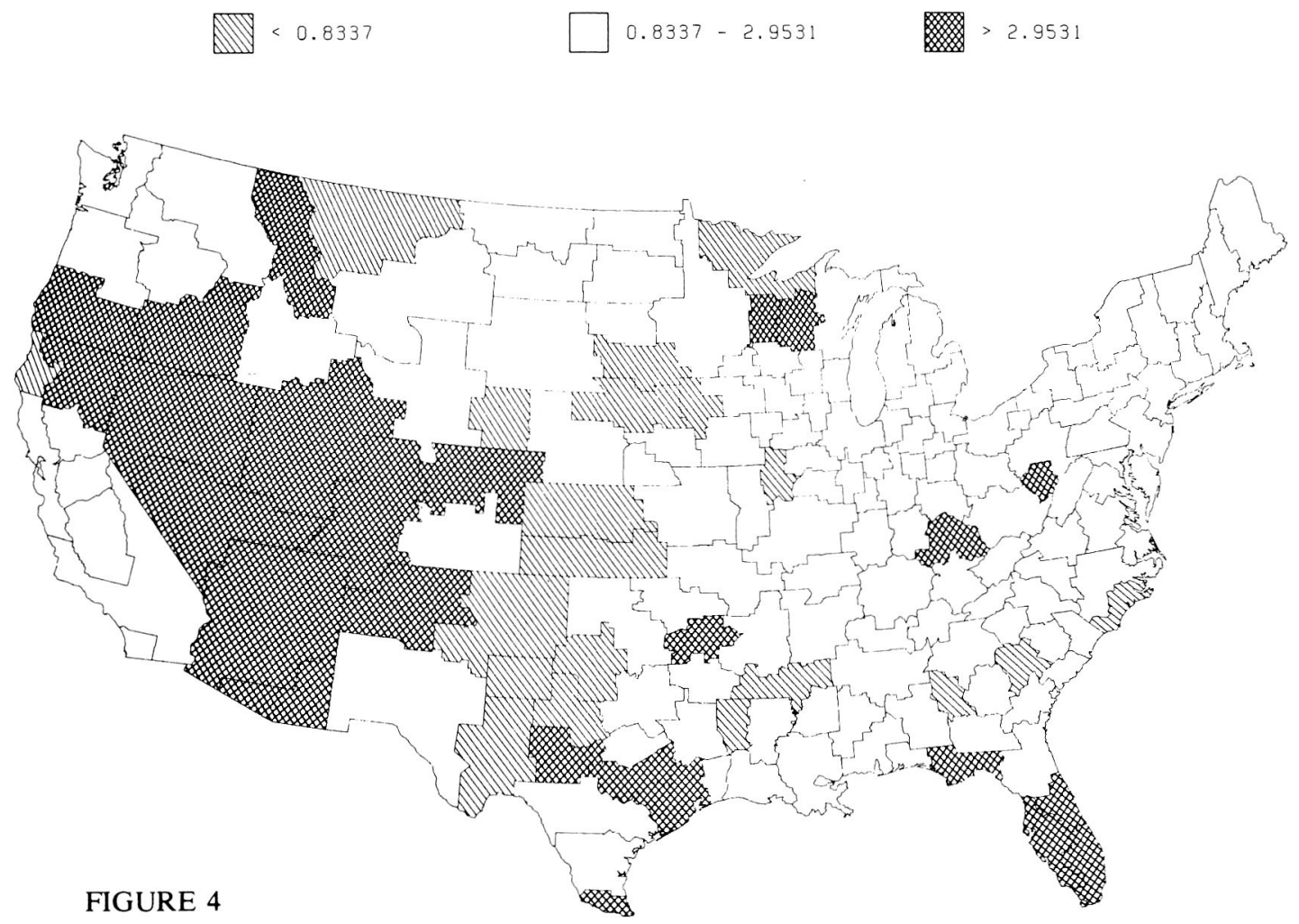

growth at the regional level is dependent upon both economic activity changes given by the MULTIREGION model, and energy consumption changes derived from the MEFS model. For example, it was observed above that a substantial portion of the projected rate of national energy growth emanated from the industrial sectors. Thus, in a spatial sense, one might expect extreme growth rates to be closely related to changes in manufacturing and resource extraction activities.

Figure 5 bears out this expectation. With the exception of parts of New England, below average increases in energy consumption are neatly clustered along the old manufacturing belt which is also projected to experience below average increases in manufacturing employment. The cluster of low energy growth regions extends pervasively into the midwest in areas where below average non-manufacturing activity growth rates are projected. Above average rates of growth for energy consumption are projected for much of the Gulf Coast, portions of the west, and portions of the South Atlantic. The coastal 


\section{GROWTH RATE OF ENERGY CONSUMPTION FROM 1975 TO 1995 MEDIUM OIL PRICE SCENARIO}

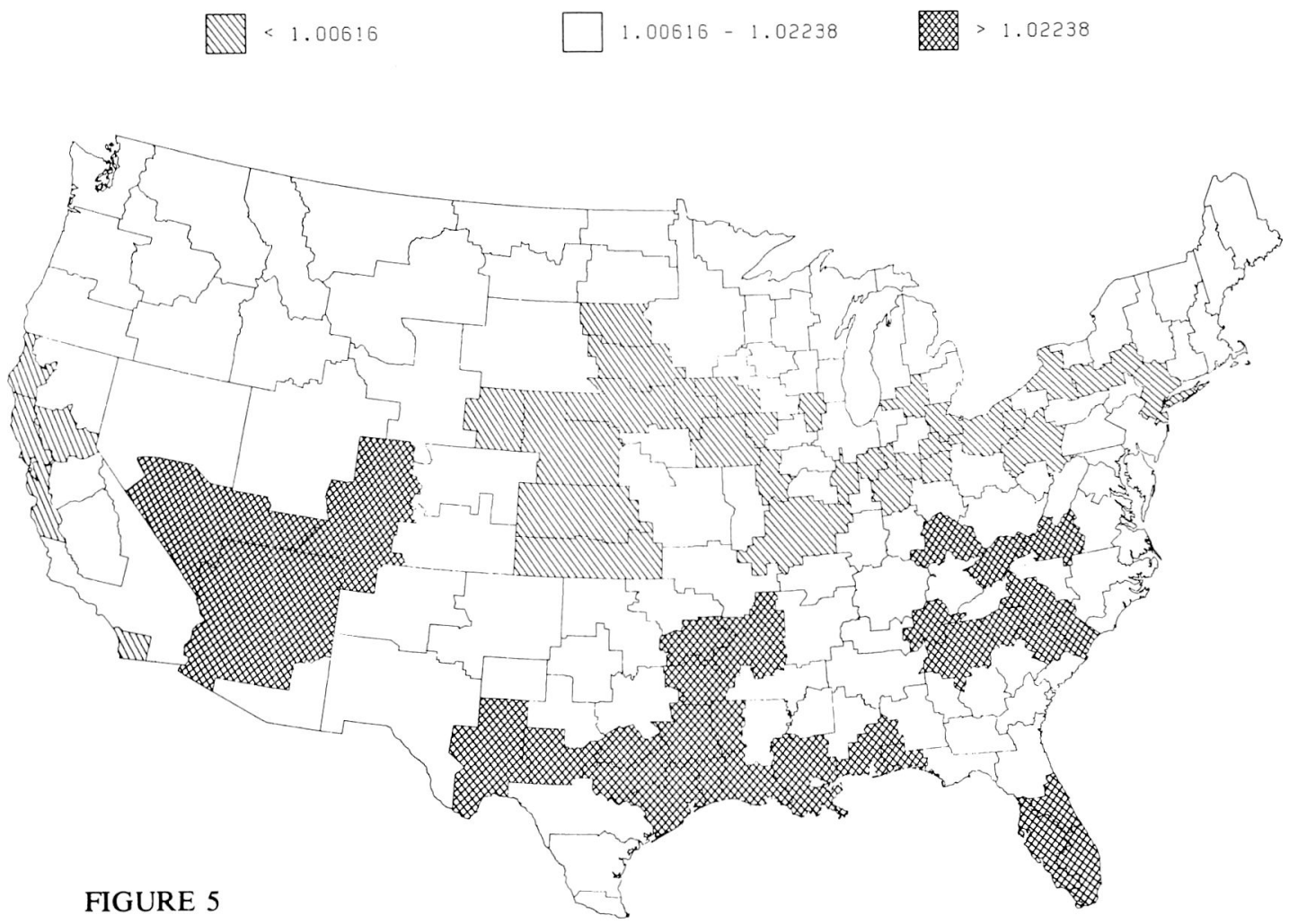

region westward from Florida is generally projected at above average growth rates in manufacturing activity, whereas Florida and the west are projected to increase in overall activity levels, led by non-manufacturing employment.

\section{Regional Impacts Under Alternative Oil Price Assumptions}

When the regional population and total employment levels for 1995 are compared under the alternate assumptions of high- and low-imported crude oil prices, only slight differences for population ( 0.2 percent) and modest differences for employment (2.8 percent) are apparent (Table 4$)$. It should be noted that national population totals, unlike national employment totals, will not change as prices for imported energy sources change. Thus, regional population changes are driven by shifts in the location of employment. These projections anticipate only slight, but relatively non-uniform, population shifts in response to the oil changes and larger, more uniform employment shifts. 
TABLE 4

Comparison of Scenario Differences in 1990 High Compared to Low [(Low-High)/High]

\begin{tabular}{lcccc}
\hline & $\begin{array}{c}\text { Mean } \\
\text { Difference } \\
\%\end{array}$ & $\begin{array}{c}\text { Standard } \\
\text { Deviation } \\
\%\end{array}$ & $\begin{array}{c}\text { BEA's* } \\
\text { Above Mean } \\
\%\end{array}$ & $\begin{array}{c}\text { BEA's* } \\
\text { Below Mean } \\
\%\end{array}$ \\
\hline Population & 0.2 & 0.4 & 10 & 2 \\
Total Employment & 2.8 & 0.7 & 9 & 6 \\
$\quad$ Manufacturing & 3.4 & 1.9 & 12 & 6 \\
Other & 2.8 & 0.9 & 11 & 5 \\
Energy Consumption & 10.4 & 5.7 & 15 & 15 \\
\hline
\end{tabular}

${ }^{*}$ Above and below average is defined as greater or less than one standard deviation from the mean.

In contrast to the regional trends explored in the earlier section, almost no spatially concentrated pattern of price-related population shifts is evident. The impacts are sufficiently small and dispersed to be safely ignored. ${ }^{10}$ Total regional employment impacts, although somewhat larger than the population impacts, are spatially similar. Again, no strong pattern of regionally concentrated impacts emerges from the spatial mappings. In fact, on a region-byregion basis, there is a substantially higher degree of uniformity associated with the scenario difference than with the dispersion among growth rates. No disçernable pattern such as could be traced out according to snowbelt-sunbelt trends is evident for the difference between scenarios, even though the general pattern of growth over time conforms to this preconception quite well.

The employment summary statistics in Table 4 indicate higher average regional differences for manufacturing than in the non-manufacturing component of total employment under the alternative scenarios. In contrast to the rather conventional portrait of snowbelt-sunbelt dispersion, the scenario differences for manufacturing employment indicated in Fig. 6 show that above-average impacts in manufacturing sector growth tend to cluster in the mountainous west, but not in regions with above or below average rates of projected manufacturing growth (see Figure 3 ). This result is quite different from the hypothesis that older, slow growth areas suffer the greatest during periods of economic change, a point which rests on the fact that the current analysis is addressing long-term rather than short-term change. This suggests that the new growth areas of the mountainous west will capture more of the national growth in a high growth case than other areas.

For non-manufacturing activity, there is no clear-cut spatial pattern of impacts visible in the scenario differences; change in these sectors due to import energy price shifts is both fairly small and uniform.

Of the variables discussed so far, energy consumption will be affected most by changes in the price of imported crude oil relative to the low price growth path. Under the high price assumptions, the average region will consume about 


\section{REGIONAL IMPACTS ON MANUFACTURING EMPLOYMENT UNOER HLTERNATIVE SCENARIOS \\ PERCENT DIFFERENCE: ( (LOW-HIGH)/HIGH)}

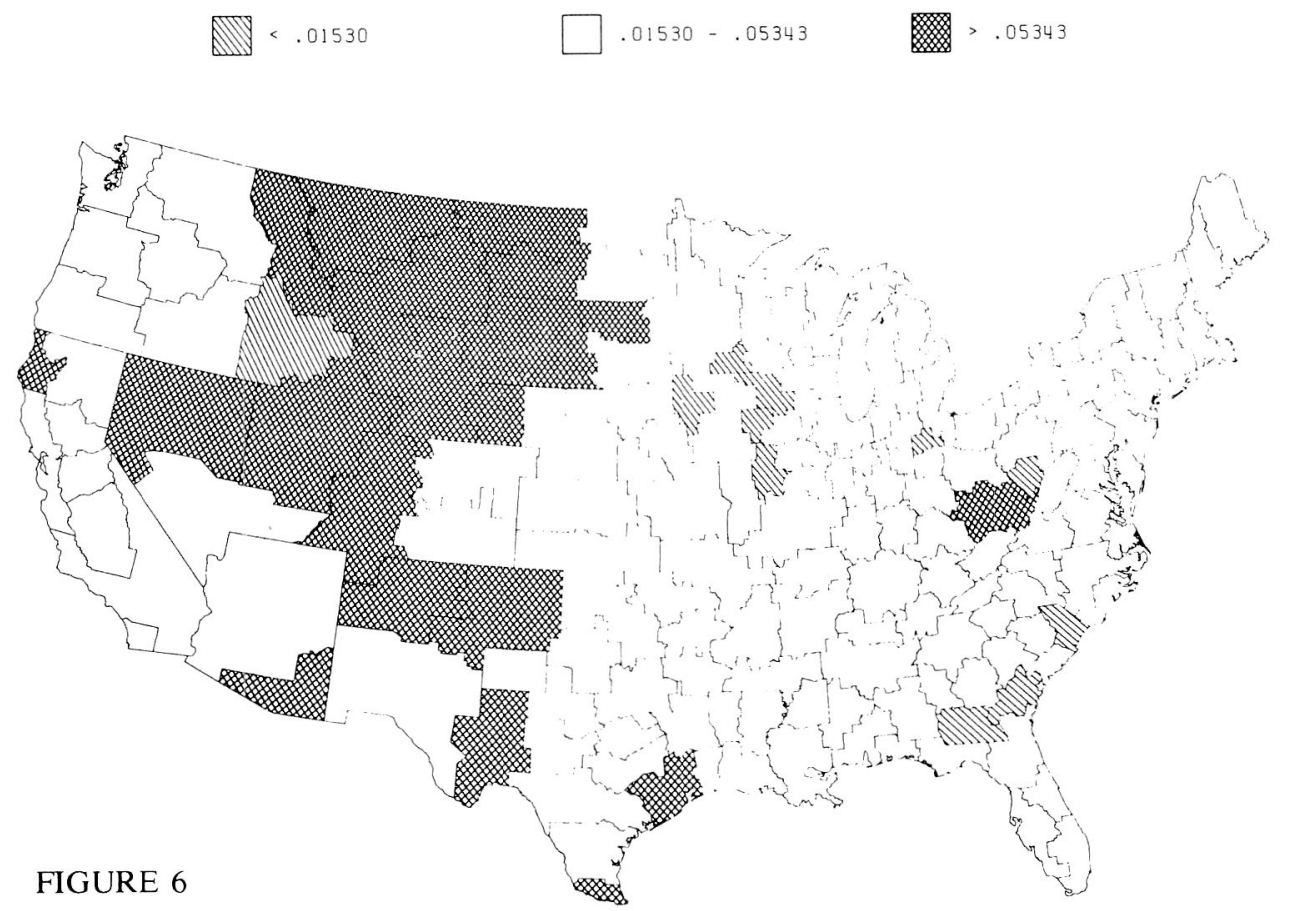

10 percent less energy. A change this large is quite significant at the regional level and implies quite different behavior in the use of energy. Moreover, as Fig. 7 shows, this change is distributed regionally such that oil and coal producing regions, which can substitute domestic production, will be affected least by import prices and such that non-producing regions heavily dependent on petroleum-based fuels, such as New England, Florida, California, and Minnesota, will receive above average changes. These latter areas will use about 16 percent less total energy than they would have under the high price assumption. It is also of interest to compare Figs. 5 and 7. The rapidly growing areas of Texas, which are also rapidly growing in fuel consumption, are projected to receive relatively small changes in fuel consumption and by implication one would expect there to be very little impact on increased economic development in this region due to import price changes. This contrasts with the findings in other work which suggest that domestic policies to increase energy prices could disproportionately affect economic development in Texas. ${ }^{11}$

When the growth path of the national economy is altered by assuming different rates of growth for imported crude oil, the changes which emerge at 


\section{REGIONAL ENERGY CONSUMPTION IMPACTS UNDER ALTERNATIVE SCENARIOS \\ PERCENT DIFFERENCE: ( (LOW-HIGH) /HIGH)}

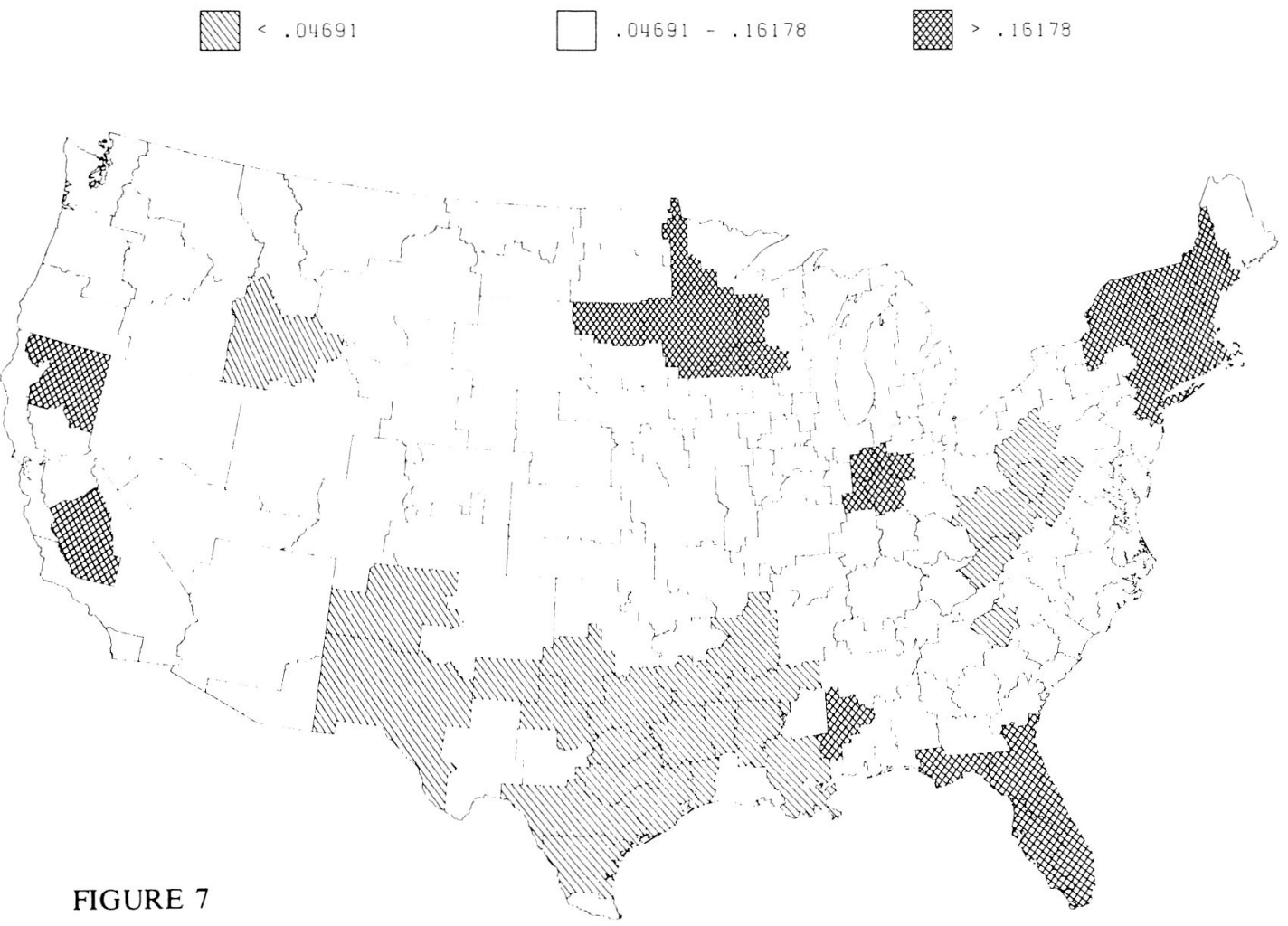

the national level are neither insignificant nor disruptive. They are instead at a magnitude which, while easily assimilated, should be avoided if possible. For manufacturing impacts, the areas of the U.S. that will be most affected tend to be high growth regions in the west, where growth is predominantly a result of non-manufacturing development. One might argue that whether or not these areas are able to capture an increased share of manufacturing growth is dependent on the performance of the national economy.

\section{CONCLUDING REMARKS}

The results of this analysis suggest that the ongoing trends which currently influence regional growth and change are likely to cause a good deal more change in the distribution of people and employment than are the prices of imported crude oil. Perhaps the most significant finding is that measured by percentage changes, the most consistent spatial impact was visible in the manufac- 
turing sector where the ability of fast growing regions to capture new manufacturing jobs dropped as imported oil prices changed. Naturally enough, areas most dependent on imported crude oil showed the largest energy consumption changes whereas producing regions showed the least. Nevertheless, the price shifts did little to influence regional economic growth to a degree that disruptively exceeded the national changes.

It is, of course, easy to criticize such results from a number of planes. Some would say the full employment assumption of the DRI model diminishes the utility of employment as an indicator of economic impacts. Others might suggest that the absence of regional price equations weakens the findings. Yet others would note that the ability of regional economies to accommodate changes over the next 20 years or so has never been in question, and that policy makers should instead concern themselves with the impacts of more near term disruptions, such as oil embargoes. All of these rebuttals contain an element of truth; nevertheless, it is of some comfort to realize that the best attempts to anticipate regional disruptions and inequities have not produced cause for alarm. It would appear that in the mid- to long-term, regional markets will assimilate the types of economic impacts produced by the fairly moderate sized price increases anticipated by this analysis.

This analysis also suggests a second finding which is perhaps more important than the first, if somewhat less exciting, and one that should be considered carefully by policy makers. Since most shifts in regional energy conditions will be driven by changes in the level and composition of economic activity during the next few decades and since these changes may be substantial, energy analysts would do well to place the "exogenous" variables in their analysis under particular scrutiny. This is seldom done, and were it done carefully, the quality of most exogenous variables would be found inadequate. It is not uncommon for regional data as obsolete as the 1972 OBERS projections to underlie substantive forecasting efforts. Few energy analysts decry the lack of such input data; instead, most press to improve endogenous portions of their models. Such practices weaken the credibility of energy forecasts and could result in the production of unsatisfactory, if not improper, analytical results.

\section{FOOTNOTES}

1. The Mid-Term Energy Forecasting System (MEFS) is the current version of what was once called the Project Independence Evaluation System (PIES), a model developed by the then Federal Energy Administration. This model is now operated by the Energy Information Administration of the Department of Energy. In preparation for its analysis of the second National Energy Plan, the DOE Office of Policy and Evaluation requested the EIA to prepare a number of scenarios of national economic and energy conditions from which the scenarios considered herein were drawn.
For documentation of the MEFS see Federal Energy Administration, Project Independence Report, U.S. Government Printing Office, Washington, DC, 1974; and Federal Energy Administration, National Energy Outlook, U.S. Government Printing Office, Washington, DC, February 1976. A description of the DRI model is given in E. A. Hudson and D.W. Jorgenson, "U.S. Energy Policy and Economic Growth 1975-2000," Bell Journal of Economics and Management Sciences 5:2, pp. 461-514, 1974.

2. See R. J. Olsen, et al., MULTIREGION: $A$ 
Simulation Forecasting Model of BEA Economic Area Population and Employment, Oak Ridge National Laboratory, ORNL/RUS-25, October 1977 and D. J. Bjornstad, "Recent Modifications to and Applications of the Oak Ridge National Laboratory MULTIREGION Model," forthcoming in D. Kresge (Ed.), conference volume, An Assessment of the State-ofthe-Art in Regional Modeling, MIT-Harvard Joint Center for Urban Studies, Cambridge, Massachusetts.

3. See D. P. Vogt, et al., "Energy Availabilities for State and Local Development: Projected Energy Patterns for 1985 and 1990," Oak Ridge National Laboratory, ORNL/TM5890/S5, November 1979.

4. See D. J. Bjornstad, D. P. Vogt, and D. N. Stuckwish, "Regional Economic and Energy Consumption Implications of the NEP-2 Base Case Scenario," Oak Ridge National Laboratory, ORNL/TM-7199 May, 1981.

5. The current analysis is conducted using the old definitions of BEA areas. Under these definitions, there are 173 areas delineated.

6. For a bibliography of energy modeling studies, see A. Ulph and M. Folie, "The Role of Energy Modeling in Policy Formation,"
Energy Systems and Policy, 2:3, pp. 311-341, 1978. A useful source of the methodology of energy modeling is $\mathrm{H}$. Brock and D. Nesbitt, "Large-Scale Energy Planning Models: A Methodological Analysis," Stanford Research Institute, Menlo Park, CA, May 1977.

7. These scenarios provide the empirical basis for the assumptions regarding future economic and energy conditions on which the second national energy plan was based. See U.S. Department of Energy, Assistant Secretary for Policy and Evaluation, Office of Analytical Services, National Energy Plan, II. Appendix C-Energy and the Economy, DOE/TIC-10203, 1979.

8. See for example, N. Grickman, Econometric Analysis of Regional Systems, Academic Press, New York, New York, 1977.

9. The energy consumption projections analyzed in this section excludes electric utility's fuel use.

10. The maps are presented in Bjornstad, Vogt and Stuckwish, Ibid.

11. D. J. Bjornstad, "Changes in Regional Economic Capacity Due to Projected Energy Price Changes," The Energy Journal, 3:1 pp. 33-58, 1982. 